\title{
Tetrahydroxystilbene Glucoside Ameliorates Infrasound-Induced Central Nervous System (CNS) Injury by Improving Antioxidant and Anti-Inflammatory Capacity
}

\author{
Xuanxuan Zhou $\mathbb{D}^{1},{ }^{1,2}$ Qian Yang, ${ }^{1,2}$ Fan Song, ${ }^{1}$ Linlin Bi, ${ }^{1}$ Jiani Yuan, ${ }^{1}$ Shaoyu Guan, ${ }^{3}$ \\ Qi Yang $\left(\mathbb{1}^{3}\right.$ and Siwang Wang $\mathbb{1}^{1,2,4}$ \\ ${ }^{1}$ Department of Natural Medicine, School of Pharmacy, Air Force Medical University, Xi'an 710032, China \\ ${ }^{2}$ Collaborative Innovation Center for Chinese Medicine in Qinba Mountain, Xi'an 710038, China \\ ${ }^{3}$ Precision Pharmacy \& Drug Development Center, Department of Pharmacy, The Second Affiliated Hospital of Air Force \\ Medical University, Xi'an 710038, China \\ ${ }^{4}$ College of Life Science and Medicine, Northwest University, Xi'an 710069, China
}

Correspondence should be addressed to Qi Yang; yangqifmmu@126.com and Siwang Wang; wangsiw@fmmu.edu.cn

Received 3 October 2019; Revised 27 November 2019; Accepted 6 December 2019; Published 11 January 2020

Guest Editor: Mansur A. Sandhu

Copyright $\odot 2020$ Xuanxuan Zhou et al. This is an open access article distributed under the Creative Commons Attribution License, which permits unrestricted use, distribution, and reproduction in any medium, provided the original work is properly cited.

Background. Infrasound is a major threat to global health by causing injuries of the central nervous system (CNS). However, there remains no effective therapeutic agent for preventing infrasound-caused CNS injury. 2,3,5,4' -Tetrahydroxystilbene-2-O- $\beta$-Dglycoside (THSG) exerts protective function against CNS injuries and may have beneficial effects on infrasound-induced CNS impairment. Methods. A mouse model with CNS (oxidative stress-induced inflammation and neuronal apoptosis) injuries was established when the mouse was exposed to the infrasound of $16 \mathrm{~Hz}$ at $130 \mathrm{~dB}$ for $2 \mathrm{~h}$ each day and the duration of treatment was $8 \mathrm{~d}$. The mice were divided into the control (CG, healthy mice), the model (MG, model mice), and the THSG (EG, experimental group, model mice treated with THSG) groups. The learning and memory impairments caused by infrasound were examined using a Morris water maze test. Lipid profiles, antioxidant biomarkers, and inflammatory cytokines in hippocampus tissue were measured by using corresponding ELISA kits. Meanwhile, BCL-2/BAX/caspase-3 signaling pathway was measured in the hippocampi and prefrontal cortex of the mouse brain using real-time qPCR and Western blot. Nissl's stain was used to measure neuronal necrosis in the hippocampi and prefrontal cortex of the mouse brain. Results. THSG significantly ameliorated the learning and memory impairments caused by infrasound. On the other hand, THSG improved lipid profiles, increased antioxidant properties by affecting the levels of superoxide dismutase (SOD), glutathione peroxidase (GSH-Px), catalase (CAT), and malondialdehyde (MDA), and displayed anti-inflammatory action via the downregulation of IL- (interleukin-) 6, IL-8, IL-10, TNF- (tumor necrosis factor-) $\alpha$, and hs-CRP (high-sensitivity C-reactive protein) in the hippocampal tissues of the mouse model $(P<0.05)$. Additionally, Nissl's stain showed that THSG inhibited infrasound-induced neuronal necrosis in the hippocampi and prefrontal cortex. Besides, THSG exerted antiapoptosis function by upregulating the level of Bcl-2 and downregulating the levels of BAX and caspase- 3 in the hippocampi. Conclusion. THSG may be an effective anti-infrasound drug against CNS injury by improving antioxidant, anti-inflammatory, antiapoptosis, and antinecrosis capacities. Further research is still needed to confirm the exact molecular mechanism.

\section{Introduction}

Infrasound is the sound with the frequencies lower than $20 \mathrm{~Hz}[1]$ and can be produced by ocean waves, earthquakes, wind, apparatuses, home utilizations, buses, cars, and so on (Figure 1), [2]. With the quick development of industry, transportation vehicles, and electrical instruments, infrasound-induced injuries have increased significantly and are not only important noise pollution anymore [3]. Wind turbine low-frequency noise is a kind of infrasound 


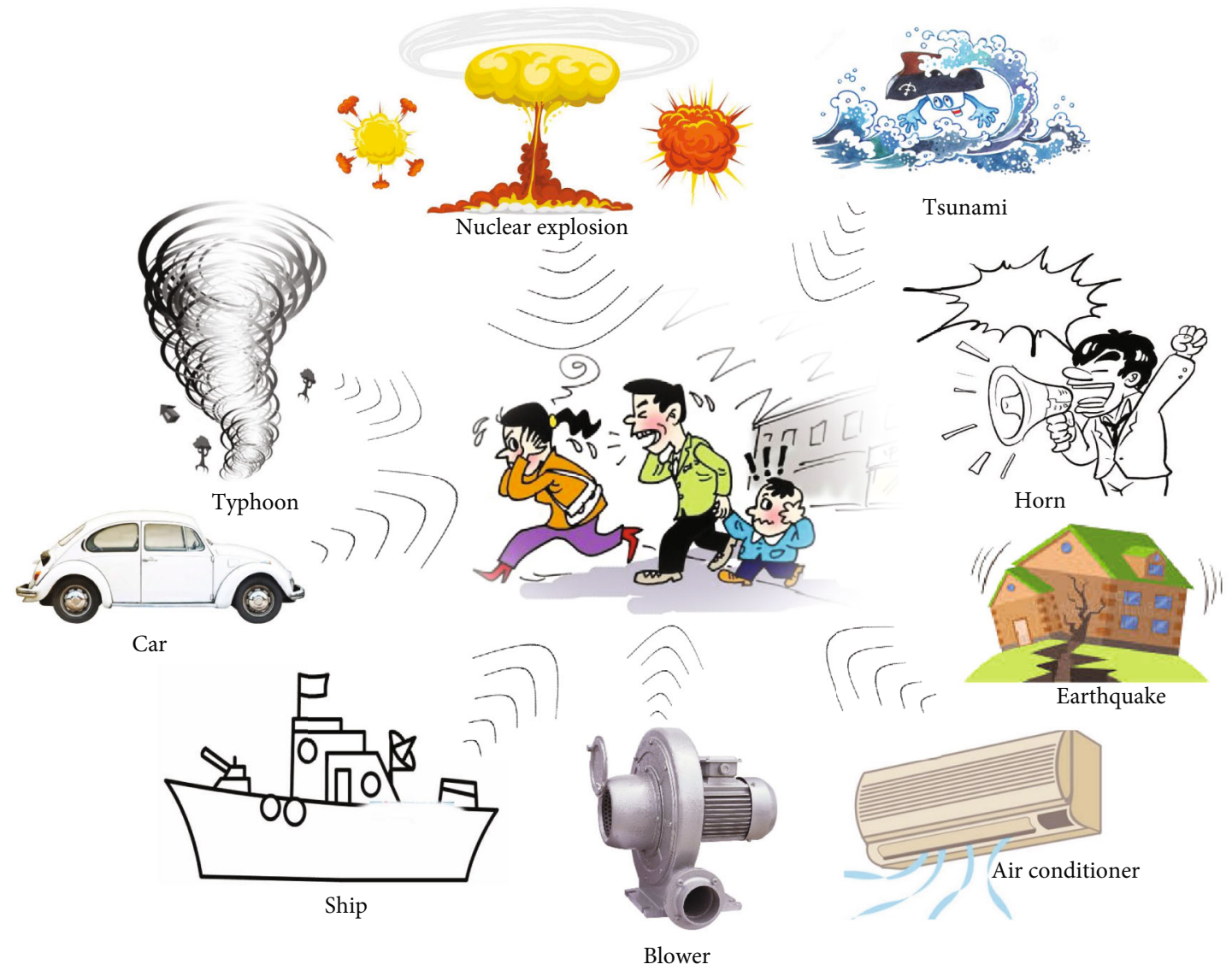

Figure 1: Categories of infrasound events.

that can produce community harmful to human health. In the field measurements, spectral peaks could be detected for $10 \mathrm{~km}$ away from wind turbines [4]. Infrasound was responsible for the onset of adverse health effects selfreported by some persons who were near with wind turbines [2]. Some relationships were found between exposure to infrasound and annoyance, sleep-related problems, concentration difficulties, and headache in the population who lived in a range of infrasound [5]. Infrasound pollution can cause human organ dysfunction and cardiac injury [6]. Animal experiments showed that infrasound destroyed hearing, cardiac, respirational, gastrointestinal, and circulation systems [7]. Particularly, infrasound impaired the central nervous system (CNS) and cognitive abilities [8].

However, it is difficult to prevent human beings from infrasound pollution because it cannot be detectable in most cases $[9,10]$. Thus, it is necessary to explore novel drugs that effectively protect CNS against infrasound-caused injury pollution. 2,3,5,4'-Tetrahydroxystilbene-2-O- $\beta$-D-glucoside (THSG) is a bioactive ingredient from a traditional Chinese herbal medicine Polygonum multiflorum Thunb (PMT). THSG has been reported to be beneficial for human health with a great number of pharmacological properties including antioxidant [11], anti-inflammation [11], free radical scavenging, and cardioprotective effects $[5,12,13]$. THSG have shown its potential for protective effects against $\beta$-amyloid deposition and memory deficits in a dementia mouse model [14]; THSG reduced cognitive impairment and inhibited the overexpression of hippocampal amyloid precursor protein (APP) [15]. THSG improved the learning and memorizing ability of aged mice and reduced senile plaque deposition induced by reducing APP [16]. Recently, we found that THSG provided protective effects by upregulating the expression of SOD and scavenging reactive oxygen species (ROS) as a potential antioxidant [17] while ROS may be associated with infrasound-induced brain injury. Infrasound-caused CNS injury was related to free radical accumulation and a high level of peroxidation in the brain cortex [18]. Infrasound exposure destroyed oxidation-antioxidant balance and increased lipofuscin accumulation in neurons of the mouse brain cortex [19]. Oxidative stress can induce apoptosis [20], and the apoptosis may result in the loss of postsynaptic proteins [21]. Postsynaptic current was modulated by postsynaptic proteins [22] while postsynaptic neurons modulate learning [23] and their dysfunction will impair memory [24]. Thus, oxidative stress can impair learning and memory by affecting postsynaptic activity.

Infrasound can affect the liver and cause the increase of lipid peroxidation $[25,26]$, which results in the changes of total cholesterol (TC), triglyceride (TG), low-density lipoprotein cholesterol (LDL-C), and high-density lipoprotein cholesterol (HDL-C) [27, 28]. Further work also showed that 
infrasound exposure increased lipid peroxidation in the kidneys [29]. On the other hand, oxidative stress is often associated with inflammatory responses [30, 31]. The interplay of oxidative and inflammation may play an important role in CNS injury.

However, little information is available in the literature regarding the mechanism of nervous protective effects for THSG against infrasound-induced CNS injury. Therefore, we performed experiments to explore the protective effects of THSG against infrasound-induced CNS injury by exploring its antioxidant and anti-inflammatory properties.

\section{Materials and Methods}

2.1. Materials. All chemical reagents with standard biochemical quality including THSG were purchased from Sigma (MO, USA).

2.2. Establishment of a Mouse Model with InfrasoundInduced CNS Injury. The experiment was approved by Animal Research Ethics Committee of the Fourth Military Medical University (Approval No. JLU24589XYZ). c57BL/6J male mice (18-20 g) were obtained from the Animal Center of the Fourth Military Medical University (Xi'an, China). The mice were given ad libitum access to food in an animal room $\left(12 / 12 \mathrm{~h} \mathrm{light/dark}\right.$ cycle at $\left.22 \pm 1^{\circ} \mathrm{C}\right)$. Infrasound instrument (Infrasonic Qigong Machine (QGM) 4.0; China Healthways Institute, San Clemente, CA, USA) was comprised of an infrasound producer and an infrasound detector. The instrument produced the infrasound with frequencies less than $20 \mathrm{~Hz}$. The mice were evenly assigned into control (CG), infrasound-induced model (MG), and THSG (EG, infrasound induction $+100 \mathrm{mg} / \mathrm{kg}$ THSG) groups, and $n=8$ in each group. THSG concentration was chosen from a previous report [32] and low concentration was used. Infrasound model was established when the mice were exposed to the infrasound of $16 \mathrm{~Hz}$ at $130 \mathrm{~dB}$ for $2 \mathrm{~h}$ each day and the whole treatment was $8 \mathrm{~d}$.

2.3. THSG Administration. THSG was solubilized in $0.85 \%$ $\mathrm{NaCl}$ solution and was administered to mice in the THSG group via intragastric administration. This experiment process was repeated for $7 \mathrm{~d}$ (intragastric administration was conducted for $24 \mathrm{~h}$ before infrasound exposure on the last day.).

2.4. Spatial Learning and Memory Test. All mice received the Morris water maze (MWM) test after the establishment of infrasound-induced CNS injury model [33]. An escaping platform was placed in the quadrant IV of a pool at one $\mathrm{cm}$ under water surface on from 1 to $4 \mathrm{~d}$ and removed on $5 \mathrm{~d}$. If a mouse could not find the platform within one min, it would be placed on the platform for $15 \mathrm{~s}$. The mice were trained for $4 \mathrm{~d}$ to find the plate. All mice were given $1 \mathrm{~min}$ to find the place where the platform was previously placed. The spatial learning scores (latency and path length) were documented.

2.5. Measurement of Lipid Profiles. After the MWM test, the mice were killed by decapitation, and the left and right hippocampi were isolated from the brain hemispheres immediately. Eight mg hippocampi were homogenized in $0.85 \%$ saline solution, lysed by using glass beads lysis (425$600 \mu \mathrm{m}$; Sigma Cat No. G-8772), and then centrifuged at $13,000 \times g$ for $10 \mathrm{~min}$ at $4^{\circ} \mathrm{C}$. Forty $\mu \mathrm{L}$ supernatants were collected to estimate the lipid profile. Mouse total cholesterol (TC) ELISA Kit (Cat. No. MBS269999), mouse triglycerides (Triglycerides, TG) ELISA Kit (Cat. No. \#MBS1601281), mouse high-density lipoprotein cholesterol (HDL-C) ELISA Kit (Cat. No. \#MBS268119), and mouse low-density lipoprotein cholesterol (LDL-C) ELISA Kit (Cat. No. \#MBS748297) were purchased from MyBioSource, Inc. (San Diego, CA, USA). The changes of lipid profiles were explored by measuring TC, TG, HDL-C, and LDL-C in hippocampus tissues on an automatic analyzer (Olympus Automated Chemistry Analyzer AU2700, Tokyo, Japan).

2.6. Measurement of Antioxidant Capacities. Above $30 \mu \mathrm{L}$ supernatants were collected to estimate the levels of catalase (CAT), malondialdehyde (MDA), malondialdehyde (MDA), superoxide dismutase (SOD), and glutathione peroxidase (GSH-Px). The levels of CAT (CAT Assay Kit, R\&D Systems Ltd., MI, USA), MDA (malondialdehyde assay kit, Beyotime Institute of Biotechnology, Beijing, China), SOD (SOD determination kit, Fluka, St. Louis, MO, USA), and GSH-Px (GSH-Px assay kit, Nanjing Jiancheng Biology Research Institute, Nanjing, China) were measured by using corresponding kits.

2.7. Measurement of Inflammatory Cytokines. Above $30 \mu \mathrm{L}$ supernatants were collected to measure the levels of inflammatory cytokines. ELISA kits for interleukin- (IL-) 6 (Cat. No. ab46100), IL-8 (Cat. No. ab46032), IL-10 (Cat. No. ab108870), and tumor necrosis factor- (TNF-) $\alpha$ (Cat. No. ab208348) were purchased from Abcam (Cambridge, MA, USA) and measured at $450 \mathrm{~nm}$ in a microplate reader (BioTek, Bad Friedrichshall, Germany). The high-sensitivity C-reactive protein (hs-CRP) was determined by immunoturbidimetry, and the test reagent was a high-sensitivity C-reactive protein reagent from Deling Company (Tangshan, China).

2.8. Nissl's Staining. Nissl's staining can show cellular necrosis [34] but not apoptosis. The increase in the number of Nissl bodies (chromatin granules) showed the reduction in neuronal necrosis [35]. Nissl staining demonstrated that the number of surviving neurons and Nissl bodies was lacking in the necrosis status of neurons [36]. Two mg hippocampi or $10 \mathrm{mg}$ prefrontal cortex (PFC) from each mouse was fixed in $10 \%$ formalin at $4^{\circ} \mathrm{C}$ for $10 \mathrm{~h}$ and cut into $300 \mu \mathrm{m}$ thick slices ( $n=8$ for each group). For histological analysis with Nissl's staining, the hippocampus or PFC slices were deparaffinized in xylene and hydrated through a series of alcohol, rinsed in distilled water, and were incubated with $0.1 \%$ cresyl violet solution for $10 \mathrm{~min}$. The neurons in the PFC and hippocampi were counted under a light microscope using $100 \mathrm{x}$ and 400x magnifications. The cells with round shape, Nissl's staining in cytoplasm, loose chromatin, and prominent nucleoli were considered as normal neurons; the cells with shrunken shape, condensed, or without Nissl's staining were considered as injured neurons. 

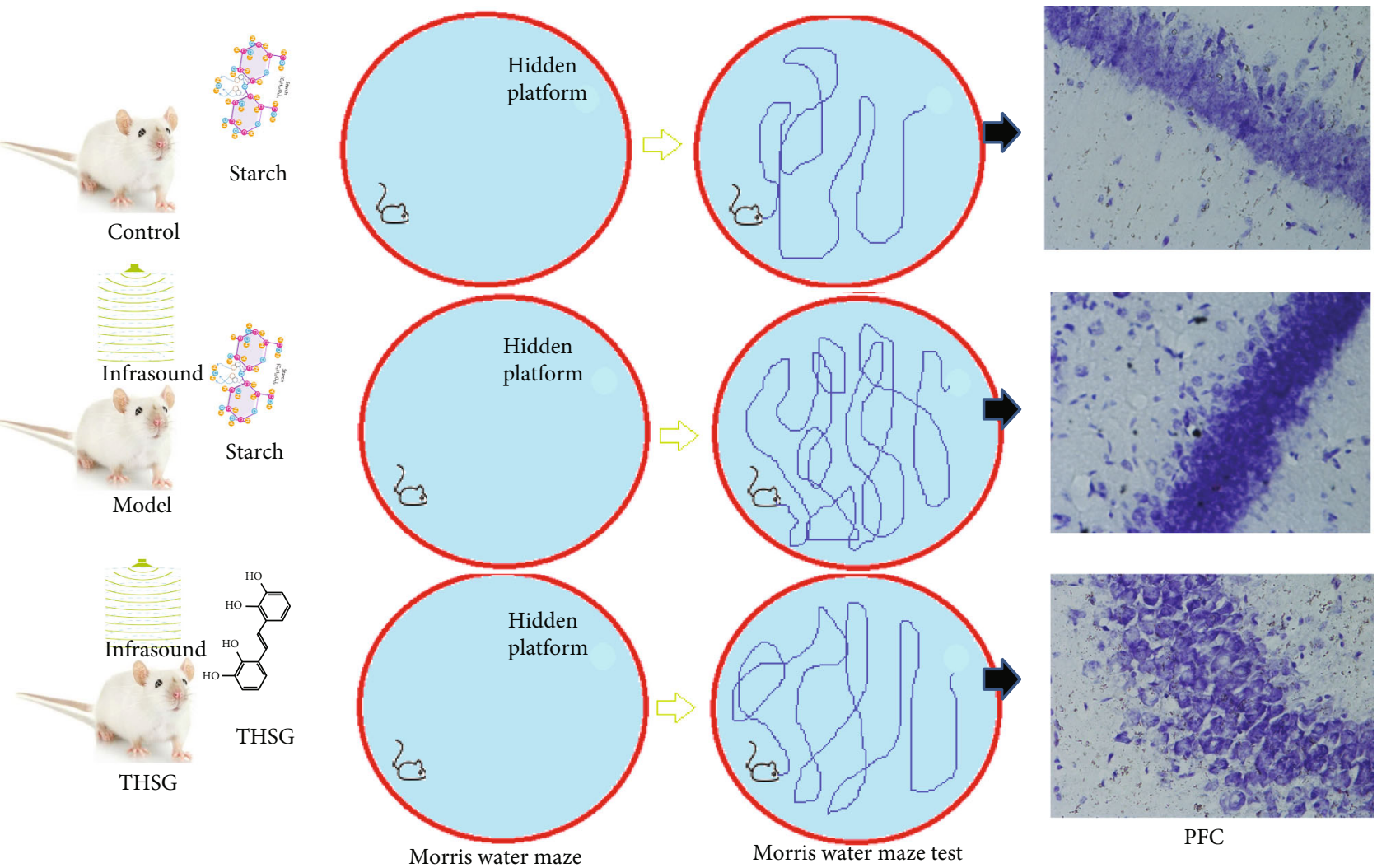

FIgURE 2: Schematic diagram of Morris water maze test among different groups. $n=8$ for each group.

2.9. RT-PCR Analysis of Apoptosis-Related Genes in the Hippocampi. Total RNA of above $50 \mu \mathrm{L}$ supernatants was extracted from by using a RNA extraction kit (TaKaRa Biotechnology (Dalian) Co., Ltd., Dalian, China). Specific primers for $B c l-2, b a x$, and caspase-3 genes were designed and synthesized by TaKaRa $(\beta$-actin, forward primer: CACGATGGAGGGGCCGGACTCATC, reverse primer: TAAAGACCTCTATGCCAACACAGT; $\mathrm{Bcl}-2$, forward primer: GGTGAACTGGGGGAGGATTG, reverse primer: GCATGCTGGGGCCATATAGT; bax, F: GGCGATGAA CTGGACAACAA, R: CAAAGTAGAAAAGGGCAACC; and Caspase-3, forward primer: GGACCTGTGGACCTGA AAAA, reverse primer: GCATGCCATATCATCGTCAG). Reverse transcription was performed as follows: $42^{\circ} \mathrm{C}, 1 \mathrm{~h}$; $95^{\circ} \mathrm{C}, 5 \mathrm{~min}$. cDNA was used for a multiplex qRT-PCR by using real-time PCR system instrument (Thermo Fisher Scientific, Waltham, MA, USA) and SYBR Green Master Mix (Applied Biosystems, Foster City, CA, USA). RT-PCR reactions were performed under the following conditions: one cycle of $95^{\circ} \mathrm{C}$ for $5 \mathrm{~min}$, followed by 45 cycles of $95^{\circ} \mathrm{C}$ for $10 \mathrm{~s}, 60^{\circ} \mathrm{C}$ for $15 \mathrm{~s}$, and $72^{\circ} \mathrm{C}$ for $20 \mathrm{~s}$. $\beta$-Actin was used as a control. Fold change was calculated as $2^{-\Delta \Delta \mathrm{Ct}}$.

2.10. Western Blot Analysis. Western blot was performed to measure relative protein levels of $\mathrm{BAX}, \mathrm{Bcl}-2$, and caspase- 3 by using above $50 \mu \mathrm{L}$ supernatants. The protein solution was separated using SDS-PAGE and transferred to a PVDF membrane (Millipore, Shanghai, China), which was blocked for $2 \mathrm{~h}$ using a $5 \%$ skim milk. The membrane was incubated with the antibodies caspase-3 (1:1000; Cat. No. \#9661), BAX (1:1000; Cat. No. \#2870), and Bcl-2 (1: 1000; Cat. No. \#2772, Cell Signaling Technology, Boston, MA, USA) at $4^{\circ} \mathrm{C}$ for $24 \mathrm{~h}$. The membranes were further incubated with a secondary antibody HRP goat-anti rabbit IgG (Thermo Scientific, Waltham, MA, USA, Cat. No 31460). Protein bands detected enhanced chemiluminescence (Millipore, Shanghai, China). The relative protein levels were calculated by using $\beta$-actin as a control. Caspase positive immunostaining was calculated by using the cut-off of $300 \mathrm{AU}$. The intensity of protein bands was examined using ImageJ software (version 2.0, NIH, MD, USA).

2.11. Statistical Analysis. All data were presented as the mean values \pm standard deviation (S.D.) and analyzed by using the software (SPSS v20.0, Stanford, CA, USA). The eEPSC current data were analyzed using Clampfit 10.3, and the average of the 10 continuous recordings was calculated as the final current amplitudes. The frequency and magnitude of mEPSC were analyzed using a Mini Analysis Program (Synaptosoft, Leonia, NJ, USA). One-way ANOVA and LSD post hoc test were used to determine the statistical difference with $P<0.05$.

\section{Results}

3.1. THSG Improved Spatial Learning and Memory Abilities. Figure 2 schematically shows that an MWM test was used among different groups, and their pathway length for finding the platform in the pool and neural necrosis was measured. 


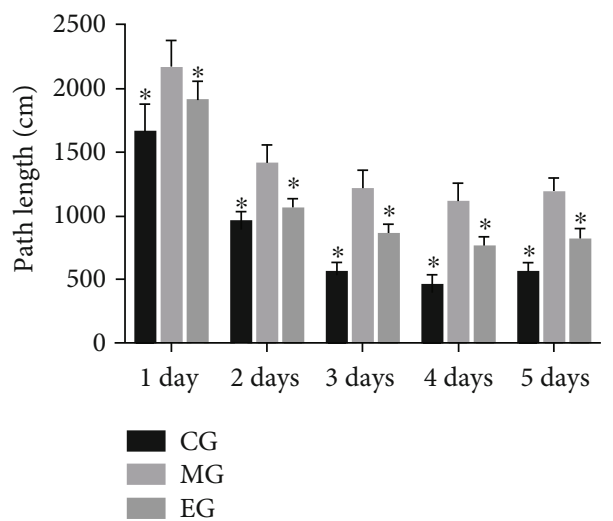

(a)

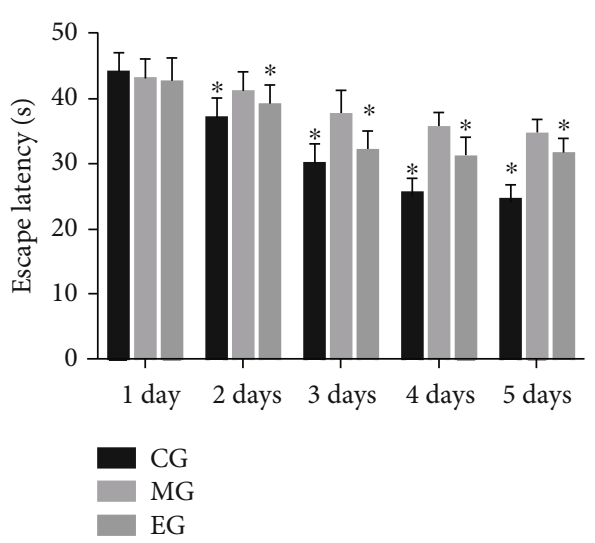

(b)

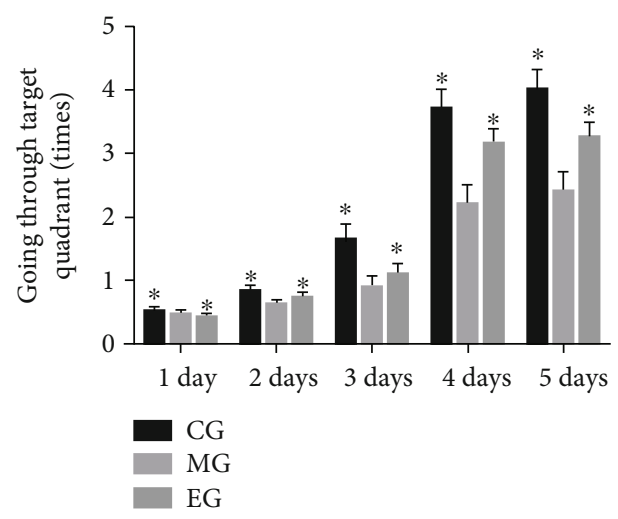

(c)

Figure 3: The effects of THSG on spatial learning and memory. (a) Path length (cm). (b) Escape latency (s). (c) The times of going through the target quadrant. $n=8$ for each group and ${ }^{*} P<0.05$ vs. the model group.

Compared to the control group, there was a significant increase in the path length in the model group, whereas THSG reduced the length (Figure 3(a), $P<0.05$ ). The mice in the control group had shorter escape latency than in the model group. THSG treatment reduced the latency when compared with the model group (Figure 3(b), $P<0.05$ ). In contrast, the mice in the control group had more times for going through target quadrant than in the model group. THSG treatment increased the times when compared with the model group (Figure $3(\mathrm{c}), P<0.05)$. The results suggested that the infrasound impaired memory ability and THSG treatment improved the symptoms.

3.2. THSG Treatment Improved Lipid Profiles. The changes of lipid profiles in mouse hippocampi after infrasound exposure were investigated. The results showed that infrasound exposure caused a dramatic decrease in the level of HDL-C in hippocampi and increased the level of TG, TC, and LDL$\mathrm{C}$ in hippocampi when compared to the normal control (Table $1, P<0.05$ ). THSG increased the brain levels of HDL-C and reduced the levels of TG, TC, and LDL-C when compared with the mouse model with infrasound-induced CNS injury (Table $1, P<0.05$ ). The results suggest that THSG treatment improved the lipid profiles of the moue model with CNS injury.
3.3. THSG Treatment Increased Antioxidant Capacities. The changes in the activity of antioxidant and oxidative biomarkers in mouse hippocampi after infrasound exposure were investigated. Higher activity of SOD, GSH-Px, and CAT is closely associated with antioxidant defense [37]. The results showed that infrasound treatment caused a dramatic decrease in the activities of SOD, GSH-Px, and CAT in hippocampal tissues, and increased the level of malondialdehyde (MDA) in hippocampal tissues when compared to the control group $(P<0.05)$. THSG increased the levels of SOD, GSH-Px, and CAT and reduced the level of MDA when compared with the CNS injury model (Table 2, $P<0.05$ ). The results suggest that THSG treatment increased antioxidant capacities of model mice.

3.4. THSG Treatment Increased Anti-Inflammatory Capacities. The changes in the levels of cytokines in mouse hippocampi after infrasound exposure were investigated. Before the model establishment and treatment, the levels of all inflammatory cytokines were similar among all groups (Table 3, $P>0.05$ ). After the model establishment, the results showed that infrasound treatment caused a dramatic increase in IL-6, IL-8, IL-10, TNF- $\alpha$, and hs-CRP when compared to the control group (Table $3, P<0.05$ ). THSG treatment reduced the levels of IL- 6 , IL- 8 , IL-10, TNF- $\alpha$, and hs-CRP 
TABLE 1: Effects of THSG on levels of TC, TG, HDL-C, and LDL-C in the hippocampus of the mice.

\begin{tabular}{|c|c|c|c|c|}
\hline Groups & $\mathrm{TC} /(\mathrm{mmol} / \mathrm{L})$ & $\mathrm{TG} /(\mathrm{mmol} / \mathrm{L})$ & $\mathrm{HDL}-\mathrm{C} /(\mathrm{mmol} / \mathrm{L})$ & $\mathrm{LDL}-\mathrm{C} /(\mathrm{mmol} / \mathrm{L})$ \\
\hline \multicolumn{5}{|c|}{ Before the model establishment and treatment } \\
\hline CG & $2.40 \pm 0.16$ & $1.22 \pm 0.11$ & $1.42 \pm 0.12$ & $1.52 \pm 0.16$ \\
\hline EG & $2.43 \pm 0.14$ & $1.20 \pm 0.12$ & $1.39 \pm 0.15$ & $1.58 \pm 0.15$ \\
\hline MG & $2.38 \pm 0.17$ & $1.19 \pm 0.13$ & $1.41 \pm 0.16$ & $1.55 \pm 0.17$ \\
\hline \multicolumn{5}{|c|}{ After the model establishment and treatment } \\
\hline CG & $2.46 \pm 0.22^{\mathrm{c}}$ & $1.23 \pm 0.15^{\mathrm{c}}$ & $1.49 \pm 0.18^{\mathrm{c}}$ & $1.69 \pm 0.22^{\mathrm{c}}$ \\
\hline EG & $2.53 \pm 0.56^{\mathrm{c}}$ & $1.27 \pm 0.18^{\mathrm{c}}$ & $1.56 \pm 0.19^{c}$ & $1.87 \pm 0.49^{c}$ \\
\hline MG & $4.2 \pm 0.60^{\mathrm{a}, \mathrm{b}}$ & $1.55 \pm 0.17^{\mathrm{a}, \mathrm{b}}$ & $1.10 \pm 0.25^{\mathrm{a}, \mathrm{b}}$ & $2.58 \pm 0.29^{\mathrm{a}, \mathrm{b}}$ \\
\hline
\end{tabular}

Note: $n=8$ for each group. ${ }^{\mathrm{a}} P<0.05$ vs. the CG group, ${ }^{\mathrm{b}} P<0.05$ vs. the EG group, and ${ }^{\mathrm{c}} P<0.05$ vs. the MG group.

TABLE 2: Effects of THSG on antioxidant capacity in the hippocampal tissues of the mice.

\begin{tabular}{|c|c|c|c|c|}
\hline Groups & $\mathrm{MDA} /(\mathrm{nmol} / \mathrm{mg})$ & $\mathrm{SOD} /(\mathrm{U} / \mathrm{L})$ & GSH-Px/(U/mg) & $\mathrm{CAT} /(\mathrm{U} / \mathrm{g})$ \\
\hline \multicolumn{5}{|c|}{ Before the model establishment and treatment } \\
\hline CG & $5.64 \pm 0.52$ & $97.62 \pm 8.23$ & $224.29 \pm 30.17$ & $50.23 \pm 2.01$ \\
\hline EG & $5.58 \pm 0.46$ & $92.53 \pm 8.12$ & $226.43 \pm 28.62$ & $48.17 \pm 1.86$ \\
\hline MG & $5.60 \pm 0.49$ & $94.68 \pm 7.87$ & $227.55 \pm 29.32$ & $52.02 \pm 2.25$ \\
\hline \multicolumn{5}{|c|}{ After the model establishment and treatment } \\
\hline CG & $5.76 \pm 0.66^{\mathrm{b}, \mathrm{c}}$ & $110.30 \pm 8.34^{\mathrm{b}, \mathrm{c}}$ & $288.5 \pm 43.76^{\mathrm{b}, \mathrm{c}}$ & $55.87 \pm 2.05^{\mathrm{b}, \mathrm{c}}$ \\
\hline EG & $7.29 \pm 1.07^{\mathrm{a}, \mathrm{c}}$ & $99.69 \pm 8.61^{\mathrm{a}, \mathrm{c}}$ & $238.28 \pm 36.88^{\mathrm{a}, \mathrm{c}}$ & $45.69 \pm 10.91^{\mathrm{a}, \mathrm{c}}$ \\
\hline MG & $8.94 \pm 2.33^{\mathrm{a}, \mathrm{b}}$ & $77.97 \pm 6.19^{\mathrm{a}, \mathrm{b}}$ & $173.12 \pm 23.51^{\mathrm{a}, \mathrm{b}}$ & $33.32 \pm 11.97^{\mathrm{a}, \mathrm{b}}$ \\
\hline
\end{tabular}

Note: $n=8$ for each group. ${ }^{\mathrm{a}} P<0.05$ vs. the CG group, ${ }^{\mathrm{b}} P<0.05$ vs. the EG group, and ${ }^{\mathrm{c}} P<0.05$ vs. the MG group.

in hippocampal tissues when compared with the CNS injury model (Table 3, $P<0.05$ ). The results suggest that THSG treatment increased anti-inflammatory capacities of the hippocampi of the model mice.

3.5. THSG Inhibited Infrasound-Induced Neuron Necrosis of PFC Region in the Mouse Model. Neuronal necrosis in mouse PFC was measured using Nissl's staining. In the control group, there were many large Nissl bodies. Compared with controls (Figures 4(a) and 4(b)), infrasound treatment induced necrotic neurons with less Nissl bodies in PFC region of the mouse model (Figures $4(\mathrm{c})$ and $4(\mathrm{~d})$ ). THSG pretreatments at $100 \mathrm{mg} / \mathrm{kg}$ THSG significantly increased the number of Nissl bodies (Figures 4(e) and 4(f)).

3.6. THSG Inhibited Infrasound-Induced Neuron Necrosis of Hippocampus Region in the Mouse Model. Nissl's staining showed that infrasound caused neuronal necrosis in mouse hippocampi. When compared with controls (Figures 5(a) and 5(b)), infrasound treatment increased the amounts of necrotic neurons compared with the control in hippocampus region (Figures 5(c) and 5(d)). THSG pretreatments $(100 \mathrm{mg} / \mathrm{kg})$ significantly increased the number of Nissl bodies (Figures 5(e) and 5(f)).

3.7. The Effects of THSG on Relative mRNA Levels of Apoptosis-Related Genes. Bcl-2 [38], BAX [39], and caspase$3[40,41]$ have been reported to be associated with oxidative stress and apoptosis. Infrasound treatment reduced relative mRNA level of $B c l-2$ and a sharp increase in relative mRNA levels of bax and caspase-3. Compared with the MG group, relative mRNA level of $B c l-2$ was increased and the levels of bax and caspase-3 were reduced in the $100 \mathrm{mg} / \mathrm{kg}$ EG group (Figure 6).

3.8. The Effects of THSG on Bcl-2/BAX/Caspase-3 Signaling Pathway. Infrasound treatment reduced $\mathrm{Bcl}-2$ level and increased the levels of BAX and caspase. Comparatively, THSG $(100 \mathrm{mg} / \mathrm{kg})$ increased the level of $\mathrm{Bcl}-2$ and reduced the levels of BAX and caspase-3 (Figure 7). THSG showed antiapoptosis activity in infrasound-induced CNS injury model by affecting the levels of Bcl-2/BAX/caspase-3.

\section{Discussion}

Infrasound is widely existed in our environment and cannot be detected directly but it can induce brain injury by increasing oxidative stress [18] and cell apoptosis in hippocampi $[42,43]$. The disorder of CNS is closely associated with infrasound effect [44]. Infrasound impaired animal learning and memory abilities [45], inhibited adult neurogenesis in hippocampi, and induced neuronal injury [46]. Cognitive ability was affected by the infrasound of $16 \mathrm{~Hz}$ at $130 \mathrm{~dB}$ [8]. Hippocampi and PFC play an important role in behavioral and cognitive psychology $[47,48]$. The present finding also demonstrated that infrasound treatment increased the oxidative stress via the upregulation of MDA and downregulation SOD, GSH-Px, and CAT (Table 2) and increased cell apoptosis via the upregulation of BAX and caspase- 3 and 
TABLE 3: Effects of THSG on inflammatory cytokines in the hippocampal tissues of the mice.

\begin{tabular}{|c|c|c|c|c|c|}
\hline Groups & IL-6 (pg/mL) & IL-8 (ng/mL) & IL-10 (pg/mL) & TNF- $\alpha(\mathrm{ng} / \mathrm{mL})$ & Hs-CRP $(\mu \mathrm{g} / \mathrm{mL})$ \\
\hline \multicolumn{6}{|c|}{ Before the model establishment and treatment } \\
\hline CG & $98.76 \pm 11.37$ & $0.38 \pm 0.18$ & $222.91 \pm 85.21$ & $2.44 \pm 1.08$ & $3.72 \pm 1.34$ \\
\hline EG & $99.08 \pm 10.24$ & $0.35 \pm 0.14$ & $228.65 \pm 78.49$ & $2.48 \pm 1.12$ & $3.86 \pm 1.26$ \\
\hline MG & $99.29 \pm 10.29$ & $0.39 \pm 0.18$ & $230.25 \pm 81.21$ & $2.46 \pm 1.10$ & $3.79 \pm 1.03$ \\
\hline \multicolumn{6}{|c|}{ After the model establishment and treatment } \\
\hline CG & $100.54 \pm 12.18^{\mathrm{b}, \mathrm{c}}$ & $0.36 \pm 0.20^{\mathrm{b}, \mathrm{c}}$ & $224.82 \pm 88.48^{\mathrm{b}, \mathrm{c}}$ & $2.52 \pm 1.31^{\mathrm{b}, \mathrm{c}}$ & $3.77 \pm 1.39^{\mathrm{b}, \mathrm{c}}$ \\
\hline EG & $108.85 \pm 12.23^{\mathrm{a}, \mathrm{c}}$ & $0.54 \pm 0.19^{\mathrm{a}, \mathrm{c}}$ & $283.50 \pm 76.39^{\mathrm{a}, \mathrm{c}}$ & $3.47 \pm 1.43^{\mathrm{a}, \mathrm{c}}$ & $5.06 \pm 1.26^{\mathrm{a}, \mathrm{c}}$ \\
\hline MG & $119.10 \pm 14.33^{\mathrm{a}, \mathrm{b}}$ & $0.62 \pm 0.23^{\mathrm{a}, \mathrm{b}}$ & $309.61 \pm 79.26^{\mathrm{a}, \mathrm{b}}$ & $3.83 \pm 1.58^{\mathrm{a}, \mathrm{b}}$ & $5.65 \pm 1.53^{\mathrm{a}, \mathrm{b}}$ \\
\hline
\end{tabular}

Note: $n=8$ for each group. ${ }^{\mathrm{a}} P<0.05$ vs. the CG group, ${ }^{\mathrm{b}} P<0.05$ vs. the EG group, and ${ }^{\mathrm{c}} P<0.05$ vs. the MG group.

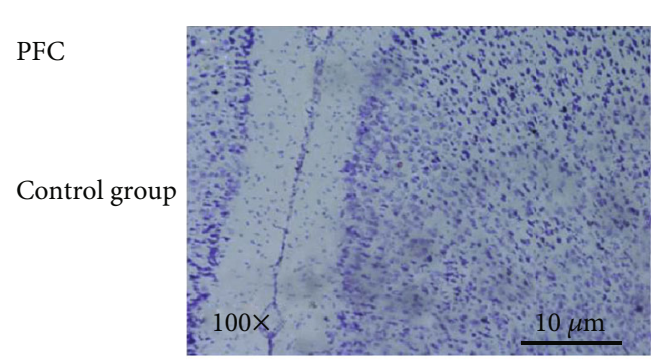

(a)

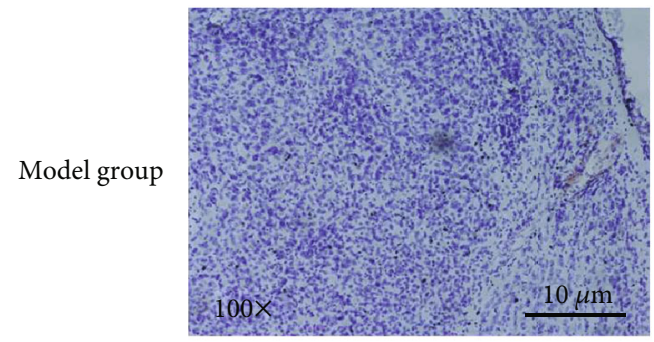

(c)

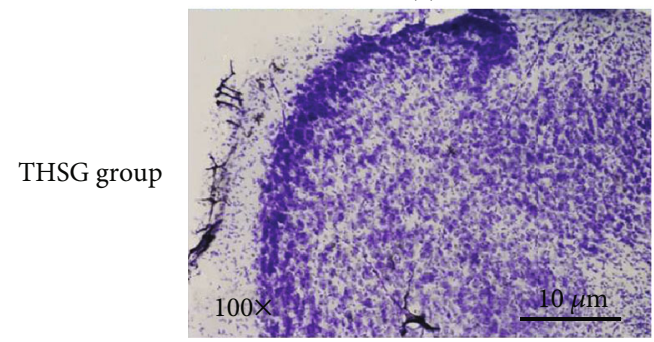

(e)

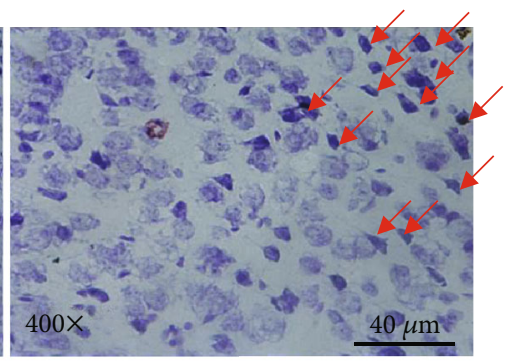

(b)

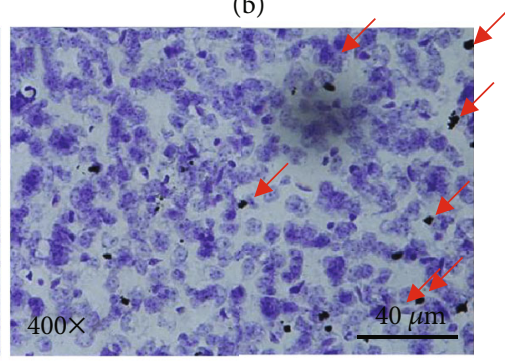

(d)

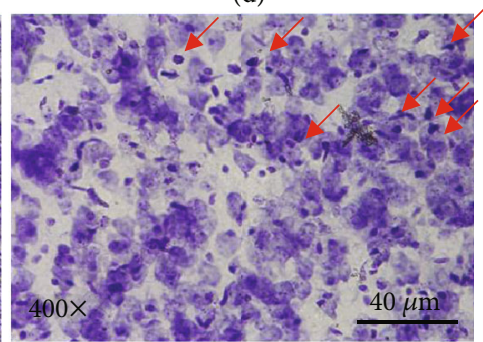

(f)

FIGURE 4: The effects of THSG on infrasound-induced neuron apoptosis of prefrontal cortices (PFC) region in the mouse model. The results were analyzed from three aspects. Quantity: the control $(a, b)$ and THSG $(e, f)$ groups had more neurons than the model group (c, d). Shape: the shapes of cells in the control group $(a, b)$ were rounder than the model group (c, d), and the cells in the THSG group (e, f) also had a more perfect shape than the model group (c, d). Definition: big cells, staining cytoplasm, loose chromatin, and prominent nucleoli were showed in the control group $(\mathrm{a}, \mathrm{b})$ while small cells and condensed or even no staining cytoplasts were observed in the model group while the situation became better in the THSG group. Nissl bodies (chromatin granules) stand for the activity of protein synthesis and showed in red arrows and are lacking in necrotic cells. $n=8$ for each group.

downregulation of Bcl-2 (Figures 6 and 7) in hippocampi and cellular necrosis in hippocampi and FPC cells. THSG treatment improved the status of cellular oxidative stress, apoptosis, and necrosis caused by infrasound.

What is the effect of THSG on animal autonomic behavior and nerve excitation? The exact mechanism remains unclear. Mammalian brain is susceptible to free radicals
[49] and ROS oxidize and disrupt brain homeostasis via the induction of cell death. Infrasound also can cause brain injury by accumulating ROS [18]. Most ROS, such as $\mathrm{OH}$, $\mathrm{H}_{2} \mathrm{O}_{2}$, and $\mathrm{O}_{2}{ }^{-}$, can be produced by infrasound [50]. Lipid accumulation is associated with ROS development [51], induces the production of mitochondrial ROS according to a previous report [52], and may increase oxidative stress in 


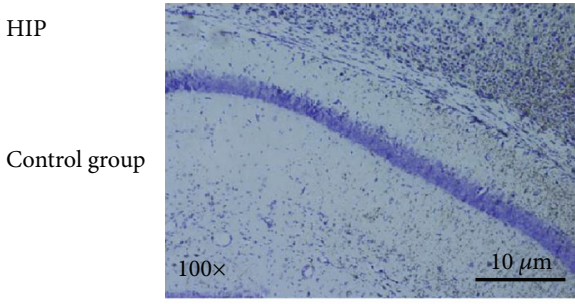

(a)

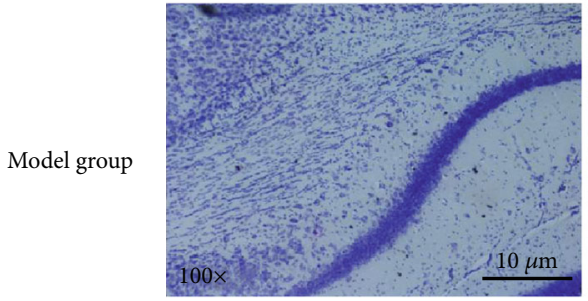

(c)

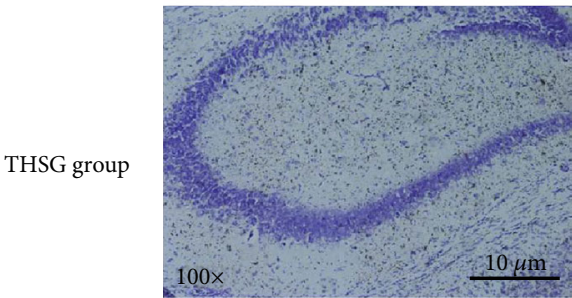

(e)

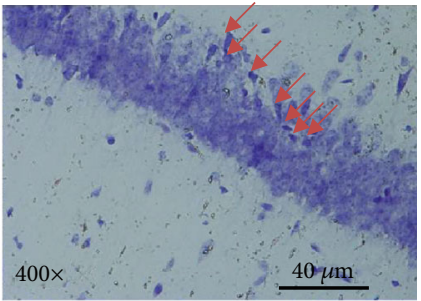

(b)

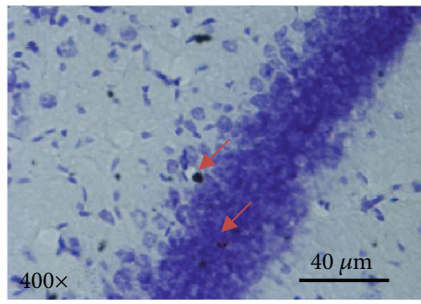

(d)

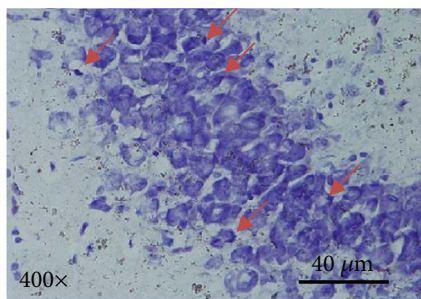

(f)

FIGURE 5: The effects of THSG on infrasound-induced neuron apoptosis of hippocampus (HIP) region in the mouse model. The results were analyzed from three aspects. Quantity: the control $(\mathrm{a}, \mathrm{b})$ and THSG $(\mathrm{e}, \mathrm{f})$ groups had more neurons than the model group (c, d). Shape: the shapes of cells in the control group (a, b) were rounder than the model group (c, d), and the cells in the THSG group (e, f) also had a more perfect shape than the model group (c, d). Definition: big cells, staining cytoplasm, loose chromatin, and prominent nucleoli were showed in the control group $(a, b)$ while small cells and condensed or even no staining cytoplasts were observed in the model group while the situation became better in the THSG group. Nissl bodies (chromatin granules) stand for the activity of protein synthesis and showed in red arrows and are lacking in necrotic cells. $n=8$ for each group.

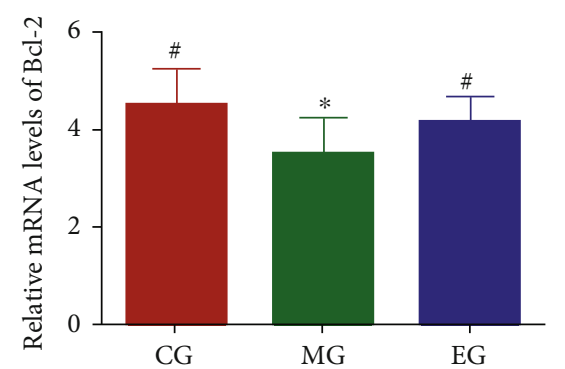

(a)

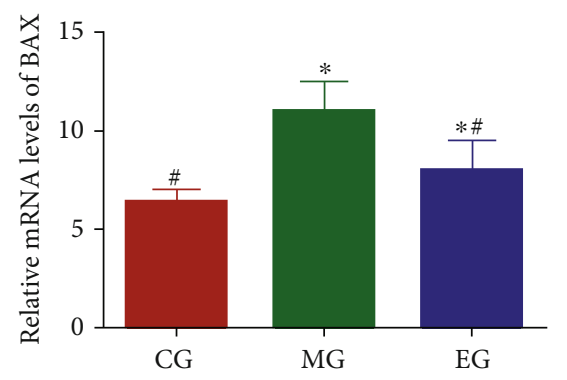

(b)

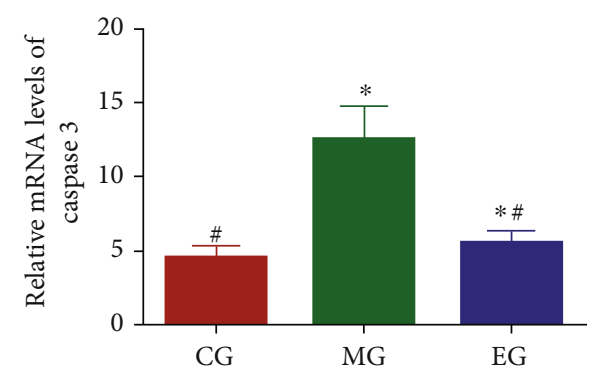

(c)

Figure 6: The effects of THSG on relative mRNA levels of Bcl-2/BAX/caspase-3. (a) The effects of THSG on relative mRNA levels of Bcl-2. (b) The effects of THSG on relative mRNA levels of BAX. (c) The effects of THSG on relative mRNA levels of caspase- 3 . $n=8$ for each group. ${ }^{*} P<0.05$ vs. the control group and ${ }^{*} P<0.05$ vs. the model group. 


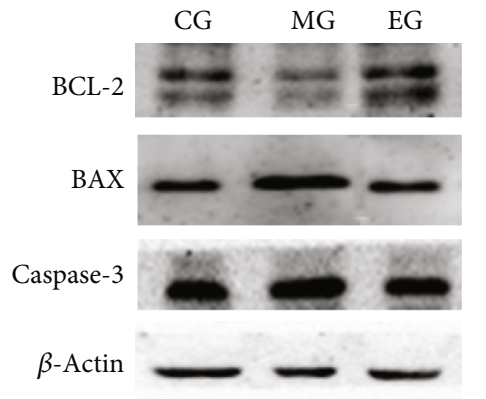

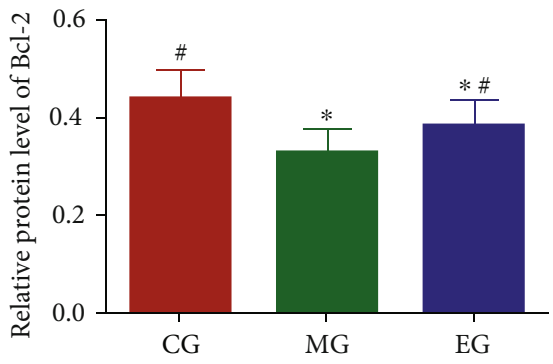

(a)

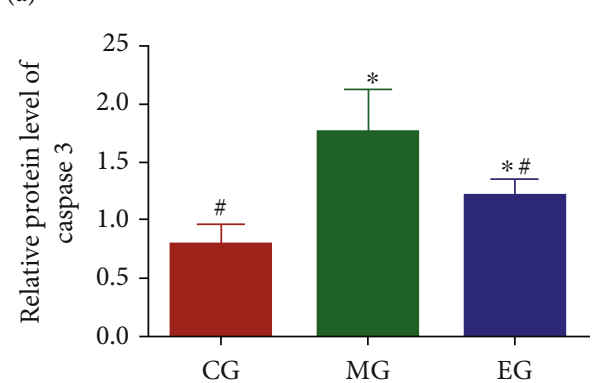

(c)

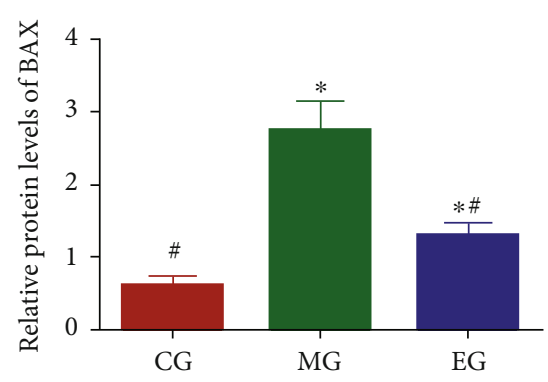

(b)

Figure 7: The effects of THSG on relative protein levels of Bcl-2/BAX/caspase-3. (a) The effects of THSG on relative protein levels of Bcl-2. (b) The effects of THSG on relative protein levels of BAX. (c) The effects of THSG on relative protein levels of caspase-3. $n=8$ for each group. ${ }^{*} P<0.05$ vs. the control group and ${ }^{*} P<0.05$ vs. the model group.

the cell. THSG therapy reduced lipid accumulation and showed potential protective agent for infrasound-induced injury as a novel ROS scavenger, a phytoestrogen. We hypothesized that the protective effect of THSG against infrasound-induced injury was their ability to counteract ROS, such as hydroxyl radical $\left(\mathrm{OH}^{-}\right)$and superoxide radical $\left(\mathrm{O}_{2}{ }^{-}\right)$, and other peroxyl radicals, and limited the oxidative injury to mouse hippocampal tissues. This process occurred because THSG slowed the accumulation of intracellular ROS, counteracted the overexpression of inducible nitric oxide synthase as well as neuronal nitric oxide syntheses [53].

Memory deficiency can be caused by inflammation [54]. Inflammation can be caused by oxidative stress, and the interplay of oxidative stress and inflammation may play an important role in the disease. Thus, THSG may have protective function for memory deficiency by improving the spatial learning and memory performance via the upregulation of anti-inflammatory properties (Table 3). Furthermore, the levels of inflammatory cytokine were increased from the CG group to the EG group and reached the highest level in the MG group (Table 3). These results suggest the potential anti-inflammatory role of THSG in the prevention of memory deficiency.

Infrasound induced neuronal apoptosis, which should be associated with memory deficiency [55]. One hundred $\mathrm{mg} / \mathrm{kg}$ THSG treatment inhibited neuronal apoptosis in mouse hippocampi (Figures 5 and 4). Bcl-2 is an important antiapoptotic factor [56], and BAX and caspase- 3 are common proapoptotic factors $[57,58]$. The present findings showed THSG treatment upregulated the Bcl-2 level and downregu- lated the level of BAX and caspase-3 (Figures 6 and 7). According to previous reports and the present findings, infrasound may increase oxidative stress and cause apoptosis in the hippocampal tissues of the animal model $[59,60]$.

There were some limitations of the present work. The present work is still limited with animal model experiments, and the effects of THSG on clinical trial of infrasoundinduced CNS injury remain unclear. THSG showed antioxidant, anti-inflammatory, antiapoptosis, and antinecrosis properties, which may be associated with specific antioxidant and anti-inflammatory signaling pathway. Thus, the exact molecular mechanism will be explored in the future work.

\section{Conclusions}

The results showed that THSG inhibited infrasound injury by reducing the path length along with escape latency and increasing the frequency of going through the target quadrant. Meanwhile, THSG improved antioxidant and antiinflammatory capacities in hippocampal tissue of the mouse models and reduced infrasound-caused neuronal apoptosis and necrosis in the hippocampi and or PFC regions. THSG may be developed a potential drug against the infrasound injury on the CNS system, but further research is still needed in the future.

\section{Data Availability}

All data can be available on the inquiry for the corresponding authors. 


\section{Conflicts of Interest}

The authors declare that they have no conflicts of interest.

\section{Acknowledgments}

This study was supported by grants from the Major Science and Technology Projects in Shanxi Province of China (2016KTZDSF01-03-03) and the National Natural Science Foundation of China (81703727).

\section{References}

[1] G. Leventhall, "What is infrasound?," Progress in Biophysics and Molecular Biology, vol. 93, no. 1-3, pp. 130-137, 2007.

[2] R. G. Berger, P. Ashtiani, C. A. Ollson et al., "Health-based audible noise guidelines account for infrasound and lowfrequency noise produced by wind turbines," Frontiers in Public Health, vol. 3, p. 31, 2015.

[3] Z. Zhuang, Z. Pei, and J. Chen, "Infrasound-induced changes on sexual behavior in male rats and some underlying mechanisms," Environmental Toxicology and Pharmacology, vol. 23, no. 1, pp. 111-114, 2007.

[4] S. E. Keith, G. A. Daigle, and M. R. Stinson, "Wind turbine low frequency and infrasound propagation and sound pressure level calculations at dwellings," The Journal of the Acoustical Society of America, vol. 144, no. 2, pp. 981-996, 2018.

[5] C. Baliatsas, I. van Kamp, R. van Poll, and J. Yzermans, "Health effects from low-frequency noise and infrasound in the general population: is it time to listen? A systematic review of observational studies," Science of The Total Environment, vol. 557-558, pp. 163-169, 2016.

[6] Z. H. Pei, B. Y. Chen, R. Tie et al., "Infrasound exposure induces apoptosis of rat cardiac myocytes by regulating the expression of apoptosis-related proteins," Cardiovascular Toxicology, vol. 11, no. 4, pp. 341-346, 2011.

[7] J. R. Ferreira, J. Albuquerque e Sousa, P. Foreid et al., "Abnormal respiratory drive in vibroacoustic disease," Revista Portuguesa de Pneumologia, vol. 12, no. 4, pp. 369-374, 2006.

[8] H. Yuan, H. Long, J. Liu, L. Qu, J. Chen, and X. Mou, "Effects of infrasound on hippocampus-dependent learning and memory in rats and some underlying mechanisms," Environmental Toxicology and Pharmacology, vol. 28, no. 2, pp. 243-247, 2009.

[9] R. Sabatini, O. Marsden, C. Bailly, and C. Bogey, "A numerical study of nonlinear infrasound propagation in a windy atmosphere," The Journal of the Acoustical Society of America, vol. 140, no. 1, pp. 641-656, 2016.

[10] X. M. Wang, "Analysis on the mechanism of acupuncture infrasound energy in treatment of diseases," Zhongguo Zhen Jiu, vol. 29, no. 3, pp. 223-226, 2009.

[11] C. Y. Jiang, X. Y. Qin, M. M. Yuan, G. J. Lu, and Y. Cheng, "2,3,5,4-Tetrahydroxystilbene-2-O-beta-D-glucoside Reverses Stress-Induced Depression via Inflammatory and Oxidative Stress Pathways," Oxidative Medicine and Cellular Longevity, vol. 2018, Article ID 9501427, 13 pages, 2018.

[12] F. Zhang, Y. Y. Wang, J. Yang, Y. F. Lu, J. Liu, and J. S. Shi, "Tetrahydroxystilbene glucoside attenuates neuroinflammation through the inhibition of microglia activation," Oxidative Medicine and Cellular Longevity, vol. 2013, Article ID 680545, 8 pages, 2013.
[13] J. K. Zhang, L. Yang, G. L. Meng et al., "Protective effect of tetrahydroxystilbene glucoside against hydrogen peroxide- induced dysfunction and oxidative stress in osteoblastic MC3T3-E1 cells," European Journal of Pharmacology, vol. 689, no. 1-3, pp. 31-37, 2012.

[14] L. Zhou, Y. Hou, Q. Yang et al., "Tetrahydroxystilbene glucoside improves the learning and memory of amyloid- $\beta_{1-42^{-}}$ injected rats and may be connected to synaptic changes in the hippocampus," Canadian Journal of Physiology and Pharmacology, vol. 90, no. 11, pp. 1446-1455, 2012.

[15] H. B. Luo, J. S. Yang, X. Q. Shi, X. F. Fu, and Q. D. Yang, "Tetrahydroxy stilbene glucoside reduces the cognitive impairment and overexpression of amyloid precursor protein induced by aluminum exposure," Neuroscience Bulletin, vol. 25, no. 6, pp. 391-396, 2009.

[16] Y. Hou, Q. Yang, L. Zhou et al., "Tetrahydroxystilbene glucoside improves learning and (or) memory ability of aged rats and may be connected to the APP pathway," Canadian Journal of Physiology and Pharmacology, vol. 89, no. 11, pp. 801-809, 2011.

[17] J. Zhao, S. Xu, F. Song, L. Nian, X. Zhou, and S. Wang, "2,3,5,4'-tetrahydroxystilbene-2-O- $\beta$-d-glucoside protects human umbilical vein endothelial cells against lysophosphatidylcholine-induced apoptosis by upregulating superoxide dismutase and glutathione peroxidase," IUBMB Life, vol. 66, no. 10, pp. 711-722, 2014.

[18] Z. Pei, R. Meng, Z. Zhuang et al., "Cardiac peroxisome proliferator-activated Receptor- $\gamma$ expression is modulated by oxidative stress in acutely infrasound-exposed cardiomyocytes," Cardiovascular Toxicology, vol. 13, no. 4, pp. 307-315, 2013.

[19] A. P. Kaban and L. M. Gunina, "Use of the indices of the kallikrein-kinin system of the blood in evaluating the efficacy of the prevention and treatment of postoperative purulent complications in oncologic patients," Klinicheskaia Khirurgiia, vol. 5, no. 5, pp. 10-12, 1989.

[20] Z. Kang, N. Qiao, G. Liu, H. Chen, Z. Tang, and Y. Li, “Copper-induced apoptosis and autophagy through oxidative stress-mediated mitochondrial dysfunction in male germ cells," Toxicol In Vitro, vol. 61, article 104639, 2019.

[21] D. D. Wang, H. Z. Zhu, S. W. Li et al., "Crude saponins of panax notoginseng have neuroprotective effects to inhibit palmitate-triggered endoplasmic reticulum stress-associated apoptosis and loss of postsynaptic proteins in staurosporine differentiated RGC-5 retinal ganglion cells," Journal of Agricultural and Food Chemistry, vol. 64, no. 7, pp. 1528-1539, 2016.

[22] W. Tao, M. H. Higgs, W. J. Spain, and C. B. Ransom, "Postsynaptic GABAB receptors enhance extrasynaptic GABAA receptor function in dentate gyrus granule cells," Journal of Neuroscience, vol. 33, no. 9, pp. 3738-3743, 2013.

[23] S. Lee, C. H. Kim, S. Oh, B. G. Park, and J. H. Lee, "Unsupervised online learning with multiple postsynaptic neurons based on spike-timing-dependent plasticity using a thin-film transistor-type NOR flash memory array," Journal of Nanoscience and Nanotechnology, vol. 19, no. 10, pp. 60506054, 2019.

[24] B. Wang, Q. Wu, L. Lei et al., "Long-term social isolation inhibits autophagy activation, induces postsynaptic dysfunctions and impairs spatial memory," Experimental Neurology, vol. 311, pp. 213-224, 2019.

[25] Y. M. Chen, L. Ye, S. B. Gao et al., "Effects of infrasound exposure on several enzymes activities of spleen and liver in rats," 
Zhongguo Ying Yong Sheng Li Xue Za Zhi, vol. 20, no. 2, pp. 176-179, 2004.

[26] A. S. Nekhoroshev and V. V. Glinchikov, "Morphological research on the liver structures of experimental animals under the action of infrasound," Aviakosmicheskaia i Ekologicheskaia Meditsina, vol. 26, no. 3, pp. 56-59, 1992.

[27] S. M. Fathy and E. A. Drees, "Protective effects of Egyptian cloudy apple juice and apple peel extract on lipid peroxidation, antioxidant enzymes and inflammatory status in diabetic rat pancreas," BMC Complementary and Alternative Medicine, vol. 16, no. 1, p. 8, 2016.

[28] N. S. Onyenibe, K. T. Fowokemi, and O. B. Emmanuel, "African nutmeg (Monodora myristica) lowers cholesterol and modulates lipid peroxidation in experimentally induced hypercholesterolemic male Wistar rats," International Journal of Biomedical Science, vol. 11, no. 2, pp. 86-92, 2015.

[29] Y. Chen, L. Ye, S. Gao et al., "Effects of infrasound on monoamine oxidase, GSH-Px, SOD and lipid peroxidation in rat kidneys," Journal of the Fourth Military Medical University, vol. 24, no. 2, pp. 113-115, 2003.

[30] F. A. Moura, M. O. F. Goulart, A. S. da Paz Martins, and S. B. G. Campos, "Close interplay of nitro-oxidative stress, advanced glycation end products and inflammation in inflammatory bowel diseases," Current Medicinal Chemistry, vol. 25, 2018.

[31] M. Del Buono, A. Abbate, and S. Toldo, "Interplay of inflammation, oxidative stress and cardiovascular disease in rheumatoid arthritis," Heart, vol. 104, no. 24, pp. 1991-1992, 2018.

[32] S. Xu, J. Liu, J. Shi, Z. Wang, and L. Ji, “2,3,4',5-tetrahydroxystilbene-2-O- $\beta$-D-glucoside exacerbates acetaminopheninduced hepatotoxicity by inducing hepatic expression of CYP2E1, CYP3A4 and CYP1A2," Scientific Reports, vol. 7, article 16511, no. 1, 2017.

[33] C. Rendeiro, A. Sheriff, T. K. Bhattacharya et al., "Long-lasting impairments in adult neurogenesis, spatial learning and memory from a standard chemotherapy regimen used to treat breast cancer," Behavioural Brain Research, vol. 315, pp. 1022, 2016

[34] S. Chen and G. Aston-Jones, "Evidence that cholera toxin B subunit $(\mathrm{CTb})$ can be avidly taken up and transported by fibers of passage," Brain Research, vol. 674, no. 1, pp. 107-111, 1995.

[35] H. Zhao, J. Mao, Y. Yuan et al., "Sodium dichloroacetate stimulates angiogenesis by improving endothelial precursor cell function in an AKT/GSK-3 $\beta / \mathrm{Nrf} 2$ dependent pathway in vascular dementia rats," Frontiers in Pharmacology, vol. 10, p. 523, 2019.

[36] M. Liu, W. Wu, H. Li et al., "Necroptosis, a novel type of programmed cell death, contributes to early neural cells damage after spinal cord injury in adult mice," The Journal of Spinal Cord Medicine, vol. 38, no. 6, pp. 745-753, 2015.

[37] A. Jankovic, L. Saso, A. Korac, and B. Korac, "Relation of redox and structural alterations of rat skin in the function of chronological aging," Oxidative Medicine and Cellular Longevity, vol. 2019, Article ID 2471312, 12 pages, 2019.

[38] Z. Zhang, H. He, Y. Qiao et al., "Tanshinone IIA pretreatment protects $\mathrm{H} 9 \mathrm{c} 2$ cells against anoxia/reoxygenation injury: involvement of the translocation of $\mathrm{Bcl}-2$ to mitochondria

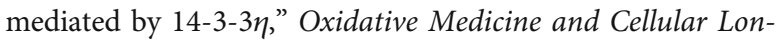
gevity, vol. 2018, Article ID 3583921, 13 pages, 2018.

[39] J. Zhang, Y. Xia, Z. Xu, and X. Deng, "Propofol suppressed hypoxia/reoxygenation-induced apoptosis in HBVSMC by regulation of the expression of Bcl-2, Bax, Caspase3, Kir6.1, and p-JNK," Oxidative Medicine and Cellular Longevity, vol. 2016, Article ID 1518738, 11 pages, 2016.

[40] A. N. Sullivan Bisson, S. A. Robinson, and M. E. Lachman, "Walk to a better night of sleep: testing the relationship between physical activity and sleep," Sleep Health, vol. 5, no. 5, pp. 487-494, 2019.

[41] F. Yu, Y. Liu, and J. Xu, "Pro-BDNF contributes to hypoxia/reoxygenation injury in myocardial microvascular endothelial cells: roles of receptors $\mathrm{p} 75^{\mathrm{NTR}}$ and sortilin and activation of JNK and caspase 3," Oxidative Medicine and Cellular Longevity, vol. 2018, Article ID 3091424, 11 pages, 2018.

[42] Z. Liu, L. Gong, X. Li et al., "Infrasound increases intracellular calcium concentration and induces apoptosis in hippocampi of adult rats," Molecular Medicine Reports, vol. 5, no. 1, pp. 73-77, 2012.

[43] M. Y. Zhang, C. Chen, X. J. Xie, S. L. Xu, G. Z. Guo, and J. Wang, "Damage to hippocampus of rats after being exposed to infrasound," Biomedical and Environmental Sciences, vol. 29, no. 6, pp. 435-442, 2016.

[44] L. Ma, H. He, X. Liu et al., "Involvement of cannabinoid receptors in infrasonic noise-induced neuronal impairment," Acta Biochimica et Biophysica Sinica, vol. 47, no. 8, pp. 647-653, 2015.

[45] C. S. Harris and D. L. Johnson, "Effects of infrasound on cognitive performance," Aviation, Space, and Environmental Medicine, vol. 49, no. 4, pp. 582-586, 1978.

[46] M. Shi, F. du, Y. Liu et al., "Glial cell-expressed mechanosensitive channel TRPV4 mediates infrasound-induced neuronal impairment," Acta Neuropathologica, vol. 126, no. 5, pp. 725-739, 2013.

[47] B. Cuccurazzu, E. Zamberletti, C. Nazzaro et al., "Adult cellular neuroadaptations induced by adolescent THC exposure in female rats are rescued by enhancing anandamide signaling," International Journal of Neuropsychopharmacology, vol. 21, no. 11, pp. 1014-1024, 2018.

[48] R. D. Rubin, H. Schwarb, H. D. Lucas, M. Dulas, and N. Cohen, "Dynamic hippocampal and prefrontal contributions to memory processes and representations blur the boundaries of traditional cognitive domains," Brain Sciences, vol. 7, no. 12, p. 82, 2017.

[49] J. S. Selvaratnam and B. Robaire, "Effects of aging and oxidative stress on spermatozoa of superoxide-dismutase 1- and catalase-null mice," Biology of Reproduction, vol. 95, no. 3, p. 60, 2016.

[50] H. Wang, J. Wang, Q. Yang et al., "Synthesis of a novel nitronyl nitroxide radical and determination of its protective effects against infrasound-induced injury," Neurochemical Research, vol. 40, no. 7, pp. 1526-1536, 2015.

[51] S. K. Verma, E. Jha, P. K. Panda et al., "Mechanistic insight into ROS and neutral lipid alteration induced toxicity in the human model with fins (Danio rerio) by industrially synthesized titanium dioxide nanoparticles," Toxicology Research, vol. 7, no. 2, pp. 244-257, 2018.

[52] K. Tsushima, H. Bugger, A. R. Wende et al., "Mitochondrial reactive oxygen species in lipotoxic hearts induce posttranslational modifications of AKAP121, DRP1, and OPA1 that promote mitochondrial fission," Circulation Research, vol. 122, no. 1, pp. 58-73, 2018.

[53] L. Tao, X. Li, L. Zhang et al., "Protective effect of tetrahydroxystilbene glucoside on 6-OHDA-induced apoptosis in PC12 
cells through the ROS-NO pathway," PLoS One, vol. 6, article e26055, no. 10, 2011.

[54] S. Shahidani, Z. Rajaei, and H. Alaei, "Pretreatment with crocin along with treadmill exercise ameliorates motor and memory deficits in hemiparkinsonian rats by anti-inflammatory and antioxidant mechanisms," Metabolic Brain Disease, vol. 34, no. 2, pp. 459-468, 2019.

[55] B. Yan, Y. Sun, J. Zeng et al., "Combined use of vitamin E and nimodipine ameliorates dibutyl phthalate-induced memory deficit and apoptosis in mice by inhibiting the ERK 1/2 pathway," Toxicology and Applied Pharmacology, vol. 368, pp. 1$17,2019$.

[56] D. Sivakumar and T. Sivaraman, "A review on structures and functions of Bcl-2 family proteins from Homo sapiens," Protein \& Peptide Letters, vol. 23, no. 10, pp. 932-941, 2016.

[57] H. Cong, N. Du, Y. Yang, L. Song, W. Zhang, and P. Tien, "Enterovirus 71 2B induces cell apoptosis by directly inducing the conformational activation of the pro-apoptotic protein Bax," Journal of Virology, vol. 90, no. 21, pp. 9862-9877, 2016.

[58] J. Ma, X. Ni, Y. Gao et al., "Identification and biological evaluation of novel benzothiazole derivatives bearing a pyridinesemicarbazone moiety as apoptosis inducers via activation of procaspase-3 to caspase-3," MedChemComm, vol. 10, no. 3, pp. 465-477, 2019.

[59] Z. S. Ataizi, K. Ertilav, and M. Naziroglu, "Mitochondrial oxidative stress-induced brain and hippocampus apoptosis decrease through modulation of caspase activity, $\mathrm{Ca}^{2+}$ influx and inflammatory cytokine molecular pathways in the docetaxel-treated mice by melatonin and selenium treatments," Metabolic Brain Disease, vol. 34, no. 4, pp. 10771089, 2019.

[60] Q. Li, P. Wang, C. Huang et al., "N-acetyl serotonin protects neural progenitor cells against oxidative stress-induced apoptosis and improves neurogenesis in adult mouse hippocampus following traumatic brain injury," Journal of Molecular Neuroscience, vol. 67, no. 4, pp. 574-588, 2019. 


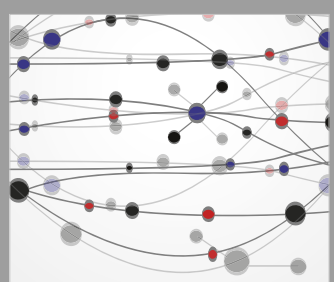

The Scientific World Journal
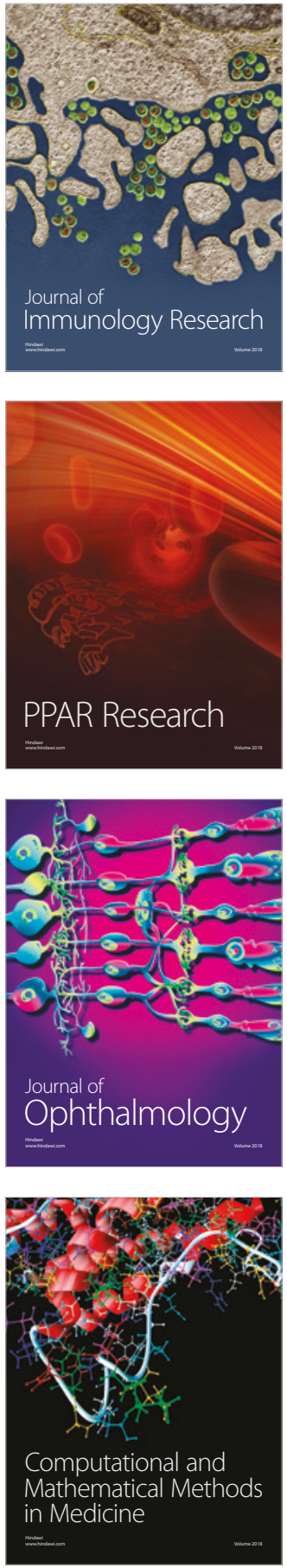

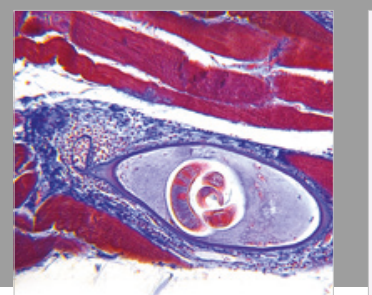

Gastroenterology Research and Practice

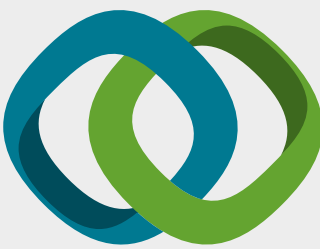

\section{Hindawi}

Submit your manuscripts at

www.hindawi.com
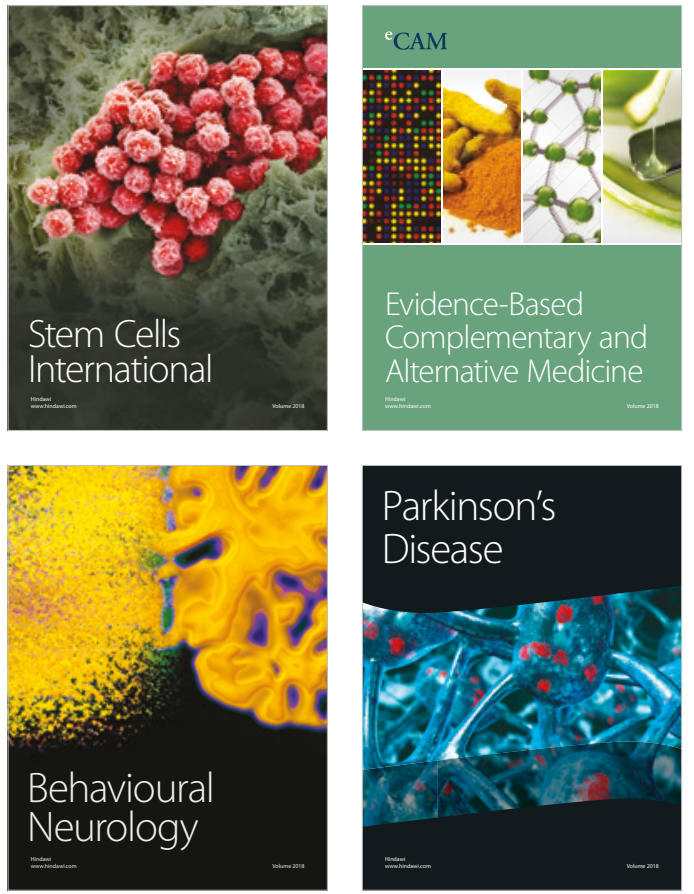

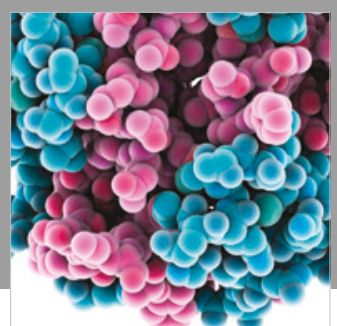

ournal of

Diabetes Research

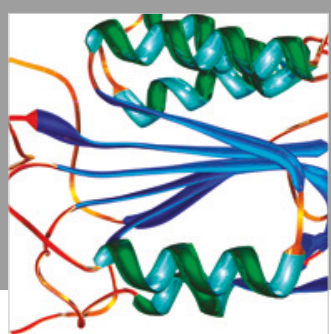

Disease Markers
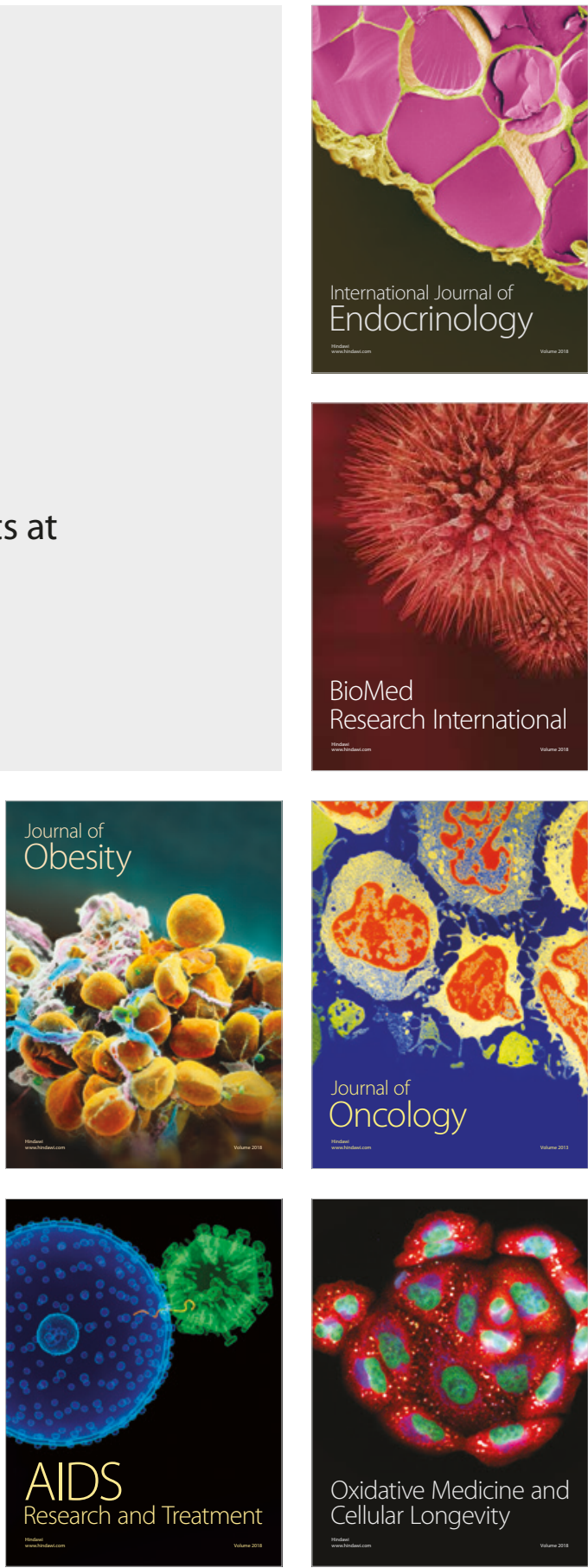